\title{
Maternalismo, políticas públicas e benemerência no Brasil $(1930-1945)^{*}$
}

\author{
Maria Lúcia Mott*
}

\begin{abstract}
Resumo
Este artigo tem por objetivos: 1. revisitar as propostas das entidades filantrópicas organizadas e administradas por mulheres na primeira metade do século XX; 2. repensar o papel que tiveram na elaboração de programas e no estabelecimento de políticas públicas; 3. chamar a atenção para a necessidade de uma releitura do movimento feminista brasileiro. O encaminhamento destes tópicos será feito a partir da análise do discurso maternalista. A pesquisa baseou-se principalmente na documentação levantada nos arquivos da Cruzada Pró Infância, entidade fundada em 1930, na cidade de São Paulo, e focalizará as propostas referentes à proteção da maternidade feitas pela sua diretora-presidente Pérola Byington, entre 1930-1945.
\end{abstract}

Palavras-chave: Maternalismo, Feminismo, Políticas Públicas, Benemerência, Pérola Byington, Cruzada Pró-Infância.

\footnotetext{
* Recebido para publicação em novembro de 2001. Este texto será apresentado, em janeiro de 2002, no International Institute of Social History, em Amsterdã no evento "Maternalism reconsidered".

** Docente de História da Enfermagem, na Faculdade Adventista de Enfermagem, São Paulo. Realiza, juntamente com Maria Elisa Botelho Byington, uma pesquisa sobre a vida de Pérola Byington e a Cruzada Pró-Infância.
} 
Maternalismo, políticas públicas e benemerência no Brasil

Maternalism, State Policy, and Women's Philanthropic Activities in Brazil (1930-1945)

\section{Abstract}

The objectives of this study are: 1 . To review the proposals of philanthropic entities, organized and managed by women in the first half of the $20^{\text {th }}$ century; 2 . To rethink the role they played elaborating programs and establishing public policies; 3 . To call attention to the need of reviewing the Brazilian feminist movement. The guide for these topics will be based on the analysis of the maternalist discourse. The research was based on documents from the archives of the Cruzada Pró Infância (Crusade Pro-Childhood) an entity founded in the city of Sao Paulo in 1930. It will focus on the proposals for maternity protection elaborated by Pérola Byington, its managing director between 1930-1945.

Key words: Maternalism, Feminism, State Policy, Philanthropic Activities, Pérola Byington, Cruzada Pró-Infância. 
Maria Lúcia Mott

I

A historiografia brasileira reconhece a importância da participação das mulheres de elite em entidades filantrópicas, nas primeiras décadas do século $\mathrm{XX}$, como forma de acesso à esfera pública, mas tem dado pouca atenção ao tema, ou ainda considerado esta atividade como menor. Em geral, é vista como uma forma das mulheres combaterem a existência tediosa e inútil, exercitarem os talentos e despenderem as energias ou como um subterfúgio para adquirirem responsabilidades fora do lar. Analisa essa participação feminina como sendo secundária, subalterna, voltada, sobretudo, para o levantamento de fundos através de festas mundanas e considera a criação e a direção das entidades, bem como as propostas norteadoras, ditadas pelos interesses masculinos e de classe. Vê a participação das mulheres casadas como uma forma de auxiliarem na projeção social e profissional de seus maridos. ${ }^{1}$

$\mathrm{O}$ mesmo enfoque recai sobre o movimento feminista organizado nas primeiras décadas do século XX. O fato de ter sido dirigido por um grupo de mulheres educadas das camadas médias $e$ das elites urbanas, de agruparem mulheres provenientes de diversas entidades, inclusive assistenciais, e por não questionarem as estruturas sociais $e$ o papel das mulheres enquanto mães $e$ donas de casa acabou resultando num certo descaso por essa historiografia, que considera que as lutas daquele período com um caráter relativamente "conservador" e "reacionário". Acrescentese a isso o fato da pesquisa histórica ter levantado o nome de

\footnotetext{
${ }^{1}$ HAHNER, J. Emancipating the female Sex. The Struggle for Women's Rights in Brazil (1850-1940). New York, Duke University Press, 1990, p.36; BESSE, S. Modernizando a desigualdade. Reestruturando a ideologia de Gênero no Brasil. São Paulo, EDUSP, 1999, pp.167-172; SCHPUN, M. Les Années Folles à São Paulo. Paris, Harmattan, Institut des Amériques Latines, 1997; WADSWORTH, J.E. Moncorvo Filho e o problema da infância: modelos institucionais e ideológicos da assistência à infância no Brasil. Revista de História, vol.19, n 37, 1999, pp.103-124
} 
Maternalismo, políticas públicas e benemerência no Brasil

algumas precursoras feministas que agiam fora do movimento organizado, como Ercilia Cobra e Maria Lacerda de Moura, cuja produção, publicada ainda na década de 1920 , era bastante crítica e discutia o papel das mulheres na família, a liberdade sexual e os direitos reprodutivos, portanto, mais alinhada com aquilo que era tido como politicamente correto pela maioria das estudiosas feministas atuantes, principalmente nas décadas 1970, 80 e 90. ${ }^{2}$

Por sua vez, as propostas de organização de uma legislação trabalhista e social no Brasil têm sido creditada à participação, em primeiro lugar, dos homens e, em segundo, das mulheres provenientes do movimento operário de diferentes tendências (anarquistas, socialistas, comunistas, etc.). A contribuição das mulheres na elaboração de propostas e no estabelecimento de políticas de bem estar social através de associações feministas e de benemerência ainda está para ser melhor estudada e avaliada.

Este artigo tem por objetivos: 1. revisitar as propostas das entidades filantrópicas organizadas e administradas por mulheres na primeira metade do século XX; 2. repensar o papel que tiveram na elaboração de programas e no estabelecimento de políticas públicas; 3 . chamar a atenção para a necessidade de uma releitura do movimento feminista brasileiro. $\mathrm{O}$ encaminhamento destes tópicos será feito a partir da análise do discurso maternalista, entendido como uma postura ideológica adotada por mulheres das camadas médias e alta nas primeiras décadas do século XX, que defendia a preponderância do sexo feminino devido a natureza específica para a maternidade, na defesa e desempenho de atividades relacionadas ao bem estar das mulheres $e$ das crianças. ${ }^{3}$ A pesquisa baseou-se principalmente na documentação

2 Leite, M.M.L. A outra face do feminismo. Maria Lacerda de Moura. São Paulo, Ática, 1984; MotT, M.L. Biografia de uma revoltada: Ercilia Nogueira Cobra. Cadernos de Pesquisa, n 58, agosto de 1986, pp.89-104.

3 Koven, S. \& Michel, S. Womanly Duties: the Origins of Welfare States. In: SCHOEMAKER, R. \& VINCENT, M. Gender and History in Western Europe. London, Arnold, 1998, pp.319-346; Bock, G. \& THANE, P. Introduction. In. Bock, G. \& 
levantada nos arquivos da Cruzada Pró Infância, entidade fundada em 1930, na cidade de São Paulo e, focalizará as propostas referentes à proteção à maternidade feitas pela sua diretora-presidente Pérola Byington, entre 1930-1945. ${ }^{4}$

\section{II}

A cronologia brasileira no que se refere aos programas $e$ políticas de bem estar social, às entidades de benemerência $e$ aos grupos feministas, tem um ritmo diferente, retardatário se comparado àquele da França, Inglaterra, Alemanha e Estados Unidos. ${ }^{5}$

Nos últimos anos do século XIX, o Brasil passou por uma série de mudanças no que diz respeito à força de trabalho $e$ ao regime de governo. Em 1888 foi abolida a escravidão e em 1889 foi proclamada a República, por militares e representantes das elites e das camadas médias urbanas de tendência positivista. A nova Constituição aprovou o federalismo, a separação entre a

Thane, P. Maternity and Gender Policies. London, Routledge, 1991, pp.1-20; WILKINSON, P. The Selfless and the Helpless: maternalism origins of the US Welfare State. Feminist Studies, fall, 1999; Sobre benemerência: LINDEMEYER, A. Public Life, Private virtues: Women in Russian Charity (1762-1914). Signs, Spring 1993, pp.562-591; SCHELl, P.A. An Honorable Avocation for Ladies. The work of the Mexico City Unión de Damas. Journal of Women's History, vol. 10, $\mathrm{n}^{\circ}$ 4, winter 1999, pp.78-99; ABEL, E. Valuing Care: Turn Century Conflits between Charity Workers an Women Clients. Journal of Women's History, vol. 10, $\mathrm{n}^{\circ}$ 3, autumn 1998, pp.32-52; DEANE, T. Late nineteenth-century philantropy. The case of Louisa Twining. In: DigBY, A. \& STEWART, J. Gender, Health and Welfare. London, Routledge, 1996, pp.122-142.

4 Pérola Byington permaneceu como diretora até 1963, ano de sua morte. Atualmente a Cruzada administra na cidade de São Paulo, 9 creches e o abrigo para crianças e adolescentes cujas famílias estão em crise.

${ }^{5}$ Koven, S. \& Michel, S. Womanly Duties... Op.cit.; Bock, G. Pauvraté Feminine, Droits des Mères et États Providence. In: DuBY, G. \& PERrot, M. Histoires des Femmes en Occident. Paris, Plon, 1992, pp.382-409; CovAS, A. Maternité et droits de femmes en France (XIX-XX siècle). Paris, Anthropos Historiques, 1997. 
Maternalismo, políticas públicas e benemerência no Brasil

Igreja Católica e Estado e o voto aberto, excluindo menores de 21 anos, analfabetos, mendigos, soldados e religiosos de ordens monásticas. Embora não fizesse menção à exclusão das mulheres do direito ao voto, somente os homens foram considerados cidadãos plenos.

O café, cultivado sobretudo em São Paulo, estado situado no Centro-Oeste do país, constituía-se, desde meados do século $\mathrm{XIX}$, na grande riqueza nacional. $\mathrm{O}$ novo governo voltou sua atenção para a expansão da economia agrária-comercial e aos interesses da oligarquia cafeeira. Investia em medidas que beneficiassem a produção e o comércio do café, como a manutenção do preço do produto, a abertura de estradas de ferro, a obtenção de mão-de-obra através da imigração subsidiada, o estabelecimento de política fiscal, a captação de recursos do exterior, a fiscalização dos portos, o combate às epidemias $e$ a repressão de movimentos sociais que pudessem obstaculizar esses interesses.

A população brasileira no período era constituída de indígenas, dos descendentes de portugueses e de africanos e de imigrantes de diversas nacionalidades que começaram a chegar em maior número por volta de 1880, destacando-se, entre eles, italianos, portugueses, espanhóis e, em menor número, alemães, suíços e norte-americanos. A partir dos anos 20, apesar da economia ainda predominantemente agro-exportadora verifica-se um significativo crescimento urbano $e$ industrial em algumas regióes do país. O Estado de São Paulo cresceu 101\%, somando mais de 4 milhões de habitantes entre 1900 e 1920. O número de estabelecimentos fabris em 1907 era de 326, empregando um total de 24.186 operários e, em 1920, 4.145 estabelecimentos com um total 83.998 operários. ${ }^{6}$

A situação dos trabalhadores brasileiros não era diferente daquela dos países europeus e dos Estados Unidos, mas os quatro

${ }^{6}$ CAROne, E. A República velha. Instituições e Classes Sociais. São Paulo, Difel, 1975, p.76. 
séculos de escravidão certamente deixaram marcas. Desde meados do século XIX, escravos e trabalhadores livres trabalharam lado a lado em diversas atividades o que influiu na maneira de patrões relacionarem-se com os trabalhadores livres $e$ na dificuldade de estruturação de movimentos de reivindicações. Nesse sentido, a chegada dos imigrantes em São Paulo teve um papel fundamental na elaboração de propostas de reforma social e na organização do movimento operário que ocorreu apenas no início do novo século, período que assistiu a estruturação do Estado nacional.

A sociedade discutia então qual deveria ser o papel do governo $e$ até que ponto poderia ou deveria intervir na vida de seus habitantes. A burocracia era rudimentar, não havia um departamento ou ministério dedicado exclusivamente às questões trabalhistas. Os hospitais pertenciam à iniciativa privada ou religiosa e o papel do Estado no campo da saúde restringia-se basicamente ao combate das epidemias e à fiscalização do exercício profissional, dos gêneros de consumo $e$ dos remédios. Intelectuais, médicos, juristas, estadistas, patrões e empregados se perguntavam a quem caberia a responsabilidade da proteção à maternidade, dos acidentes de trabalho, da saúde e da aposentadoria dos trabalhadores - se ao Estado, aos empregadores, aos empregados ou à benemerência. ${ }^{7}$

O percurso do estabelecimento das leis sociais no Brasil foi longo, sendo obtido através da luta de homens e mulheres provenientes de diferentes grupos. Sofreu forte resistência por parte dos grupos politicamente hegemônicos, o que forçava o incipiente estado a considerar as reivindicações dos trabalhadores "como caso de polícia" e a agir como tal. Até mesmo a elite dirigente que reivindicava leis sociais foi reprimida. Em 1917, o deputado Maurício de Lacerda propôs um esboço de legislação

7 LiMA, R. A maternidade. Rio de Janeiro, 1904; FERREIRA, C. Obras e fatores de preservação e assistência à infância. Imprensa Médica, vol. 15, nº 7, 10/4/1907, pp.117-123. 
Maternalismo, políticas públicas e benemerência no Brasil

social: limite de jornada de 8 horas de trabalho, 14 anos para o trabalho do menor, regulamentação do trabalho dos aprendizes, condições de trabalho para as mulheres, criação de creches. A conseqüencia de tal proposta foi sua expulsão do Partido Republicano e a perda do mandato. ${ }^{8}$

Muitos projetos foram enviados ao legislativo, mas poucos se tornaram realidade. As leis que chegaram a ser votadas, em geral, não diziam respeito a todas as categorias, nem abrangiam todo o território nacional e, quando aprovadas, freqüentemente permaneciam como letra morta. Os primeiros trabalhadores a serem beneficiados foram os funcionários públicos que trabalhavam na construção de estradas de ferro e nos ministérios relacionados ao abastecimento de água e transportes.

Quanto a proteção à infância e à maternidade, alguns autores consideram que o Brasil teve um papel precursor. ${ }^{9} \mathrm{~A}$ argumentação baseia-se no fato de em 1822, ainda durante a monarquia, José Bonifácio de Andrade e Silva ter elaborado um projeto de lei no qual regulamentava o trabalho dos escravos, inclusive das escravas grávidas e das crianças. Pelo projeto, a escrava depois de completar três meses de gravidez estava proibida de realizar trabalhos pesados e violentos. Após o oitavo mês a atividade deveria ficar restrita ao serviço da casa e depois do parto deveria ter um mês de convalescença. O filho deveria permanecer junto da mãe durante um ano. A lei previa ainda que até os 12 anos os escravos não fossem empregados em trabalhos insalubres e excessivos. ${ }^{10}$ Vale destacar que em 1834 a parteira Mme. Durocher enviou à Câmara Municipal da cidade do Rio de

8 PENA, M.V.J. Mulheres e trabalhadoras. Presença Feminina na constituição do sistema fabril. Rio de Janeiro, Paz e Terra, 1981; CARONE, E. A República velha. Instituições e Classes Sociais. São Paulo, Difel, 1975; Gomes, A.C. A invenção do trabalhismo. Rio de Janeiro, IUPERG/Vértice, 1988.

9 Magalhães, F. A Obstetrícia no Brasil. Rio de Janeiro, Leite Ribeiro, 1922 , pp.213-4.

${ }^{10}$ Malheiro, P. A escravidão no Brasil. Ensaio Histórico, Jurídico, Social. Petrópolis, Vozes, 1976, vol. 2, pp.228-31. 
Janeiro, então capital do Império, um projeto de inspeção de amas de leite - que no período eram, em sua maioria, escravas com o objetivo de combater a mortalidade infantil. ${ }^{11}$ Como os dois projetos não iam de encontro aos interesses dos senhores de escravos nenhum deles chegou a ser aprovado.

A cidade do Rio de Janeiro, pouco tempo após a proclamação da República, foi o primeiro local a regulamentar o trabalho de menores. ${ }^{12}$ Três anos depois, em 1894, o legislativo do Estado de São Paulo, por sua vez, através do código sanitário, estabeleceu uma série de regras sobre a higiene do trabalho limite de idade para o trabalho infantil, proibição de trabalho noturno de mulheres e crianças, salubridade do local de trabalho, obrigatoriedade dos trabalhadores serem vacinados contra varíola. A partir de 1910, em algumas cidades, as professoras primárias obtiveram dois meses de licença maternidade com vencimentos e proibiu-se o trabalho das mulheres no último mês de gravidez e no primeiro do puerpério. ${ }^{13}$

Pode-se dizer que a grande maioria dos trabalhadores até os anos 1920 não tinha regulamentado salário, horário de trabalho, dias a serem trabalhados, férias, acidentes de trabalho, aposentadoria, licença maternidade, limite de idade para o trabalho dos menores. Esses benefícios, e o sufrágio feminino, só foram estabelecidos em nível nacional nas décadas de 1930 e 1940.

\footnotetext{
${ }^{11}$ MotT, M.L.B. Parto, parteiras e parturientes no século XIX: Mme. Durocher e sua época. Tese de Doutoramento, Departamento de História, FFLCH/USP, 1998.

12 PENA, M-V.J. Mulheres e trabalhadoras... Op. cit., p.153; BlAnCO, E.L. O trabalho da Mulher e do Menor na Indústria Paulista. Dissertação de Mestrado, Departamento de História, FFLCH/USP, 1977.

${ }^{13}$ Dordal, A.R. A proteção da operária grávida. São Paulo, P.M. Higgins, 1923. Tese defendida na Faculdade de Medicina e Cirurgia de São Paulo, p.11; SouZA, O. Aspecto Social da Assistência Obstétrica. Relatório, Primeiro Congresso de Ginecologia e Obstetrícia, pp.72-8.
} 
Maternalismo, políticas públicas e benemerência no Brasil

III

A jornalista Josefina A. Azevedo, num editorial de 1892, em um dos mais importantes jornais dedicados ao sexo feminino publicado no período, intitulado $A$ Família, conclamava as mulheres a se organizarem em uma federação para melhor lutarem por seus direitos. Diferentemente do que ocorreu nos Estados Unidos, na França, na Alemanha e na Inglaterra, ao longo de quase todo o século XIX, foram raras as possibilidades das mulheres brasileiras se reunirem - em clubes, sociedades religiosas, de caridade, benemerentes, educacionais e de reforma $e$ promoção social - para discutirem questões que dissessem respeito ao bem comum ou ao interesse do próprio sexo. ${ }^{14}$ Dentre os poucos lugares de encontro e discussão devem ser lembradas as agremiações literárias, as reuniões internas dos jornais e revistas femininas, sociedades abolicionistas e associações de caridade. ${ }^{15}$

Isolamento, reduzidas oportunidades educacionais, força da autoridade masculina, medo de ir contra os costumes e cair no ridículo ou serem alvo da maledicência pública, desconfiança do clero masculino católico devido ao celibato, precariedade do meio urbano que não favorecia o convívio social, dificuldades de acesso aos bens de consumo - a maioria dos produtos usados no dia a dia eram produzidas em casa pelas mulheres, o que tornava a jornada de trabalho longa cansativa - são algumas das hipóteses que podem ser levantadas para o pequeno número de grupos associativos femininos no período.

O número de grupos e associações fundadas, organizadas $e$ administradas por mulheres só aumentará no período republicano. Até então, a denúncia e a luta das mulheres brasileiras contra a

${ }^{14}$ FerReIRA, T. Subsídios a História da Assistência Social em São Paulo (obras do Império). Monografia de conclusão de curso, Escola de Serviço Social do Centro de Estudos de Ação Social de São Paulo, 1940.

${ }^{15}$ Sobre as oportunidades das mulheres se reunirem no século XIX, ver verbetes: Schumaher, S. \& BraziL, E.V. Dicionário Mulheres do Brasil de 1500 até a atualidade. Rio de Janeiro, Zahar, 2000. 
opressão social que sofriam foi realizada basicamente através da publicação de livros e da imprensa. A professora Nísia Floresta foi uma precursora. Em 1832, fez uma tradução livre do livro de Mary Wollstonecraft, Vindication of the Rights of Women, na qual incluia reflexões sobre a situação das mulheres brasileiras. Autora de vários outros livros, Nísia Floresta defendia a educação moral e a instrução feminina para o melhor desempenho dos papéis de esposa e mãe. Viveu muitos anos na Europa, onde se relacionou com os mais renomados escritores de seu tempo, como George Sand, Dumas (pai), Lamartine e Auguste Comte. No Brasil, no entanto, foi vítima da maledicência e do descaso. ${ }^{16}$

Os jornais editados por mulheres começaram a circular a partir de 1850. Abordavam assuntos diversos e traziam notas $e$ comentários sobre as conquistas do sexo feminino nos Estados Unidos e Europa, possibilitando às leitoras brasileiras tomar conhecimento sobre a movimentação feminista em outros países. Nem todas as articulistas demonstravam ter a mesma opinião sobre todos os assuntos, mas pode-se dizer que a educação feminina e a importância da maternidade foram dois dos principais temas discutidos pelas editoras e colaboradoras desses jornais.

A educação das mulheres era defendida, seja para o progresso da nação, para o desenvolvimento da inteligência $e$ das aptidões femininas, ou como forma de realização pessoal, de obterem sustento - na falta do pai ou do marido -, para conseguirem a emancipação $e$, sobretudo, para melhor desempenharem a função de mãe de família, pois era com as mães que os filhos deveriam aprender as primeiras lições $e$ os princípios morais.

Os livros e jornais escritos e publicados por mulheres contribuíram para a divulgação da importância da mulher como mãe. Essa valorização era algo que vinha sendo cuidadosamente

${ }^{16}$ Duarte, C.L. Os primórdios do feminismo no Brasil. In: Floresta, N. Direitos das Mulheres e Injustiça dos Homens. São Paulo, Cortez, 1989, pp.99-134. 
Maternalismo, políticas públicas e benemerência no Brasil

construído na sociedade brasileira desde meados do século XIX. Uma metáfora freqüentemente encontrada nos textos escritos pelas mulheres sobre a condição feminina é a da escrava. A grande batalha era pelo fim da tirania a que eram submetidas pelos maridos, pais e irmãos e pelo reconhecimento de sua importância devido à maternidade. A natureza feminina, segundo elas, atribuía às mulheres características específicas para a maternidade, o que fazia com que marido e esposa tivessem funções igualmente importantes, embora diferentes e exercidas em esferas distintas. O exercício do papel de mãe era visto como uma forma de patriotismo. Em 1852, Joana Paula Manso, no editorial do Jornal das Senhoras, dizia:

Nós sabemos perfeitamente que toda família necessita de um chefe, e que o chefe natural da família é o homem. Sem dúvida que há deveres que prendem a mulher ao lar doméstico, porém é precisamente desde o seio de sua família que ela pode ter uma influência direta sobre a nação, sobre a humanidade inteira.

E em 1873, Francisca S. M. Diniz, no editorial do jornal $O$ Sexo Feminino, assim justificava a importância da educação das mulheres:

A mulher dotada com as mesmas faculdades do homem, com inteligência e a razão abertas a receber o cultivo das letras, das artes e das ciências, para ser útil à pátria $e$ desempenhar sua missão na sociedade, a maior $e$ a mais santa missão que depende toda da mãe de família, deve chamar a si os foros que não pode negar-lhe a sociedade culta. Instrução para o sexo feminino, minhas caras patrícias! ${ }^{17}$

${ }^{17}$ ALMEIDA, A. M. Maternidade e Cidadania: uma encruzilhada para as primeiras feministas. ANPOCS, Águas de São Pedro, 1985, mimeo., p.1. 
Na virada do século XX, o reconhecimento da importância das mulheres devido à maternidade já estava solidificado na sociedade brasileira e era aceito por homens e por mulheres. $\mathrm{O}$ discurso das esferas separadas tinha cumprido seu papel. Se essa qualidade - a "natureza feminina" - foi usada em muitos casos para segregar as mulheres ao lar e como argumento para impedir a obtenção de direitos civis, políticos, econômicos, intelectuais e sociais, começou também a ser usada num sentido inverso: para lhes abrir as portas e levar as aptidões maternas para fora de casa, para o exercício de determinadas profissões consideradas próprias às mulheres, como a assistência social compatível com a "missão altruística" das mães e, até mesmo, para o exercício dos direitos políticos devido a uma "moralidade" específica ao sexo feminino. ${ }^{18}$

Com o advento da República, os periódicos femininos passaram a defender o sufrágio e algumas mulheres reivindicaram na prática esse direito. Em 1890, a dentista Isabel Dillon alistou-se para votar e, através das páginas do jornal $A$ Família, se apresentou como candidata para a Constituinte Republicana. Baseou sua candidatura no argumento da lei eleitoral que, ao estabelecer o voto para todos os cidadãos maiores de 21 anos que soubessem ler e escrever, não excluía as mulheres. Foi uma das primeiras mulheres brasileiras a propor leis de proteção à infância, à maternidade, visto serem esses tópicos de seu programa. ${ }^{19}$

\footnotetext{
${ }^{18}$ Francisca S. M. Diniz assim se referia ao sufrágio feminino: "O verbo eloqüente da palavra na tribuna parlamentar não nos deve ser negado em seu direito. (...) Lembrem-se que a mulher deve subir à tribuna e advogar a sua causa, isto é, a causa do direito, da justiça e da humanidade, lembrando-se que ela como mãe representa a santidade do amor infinito". DINIZ, F.S.M. Igualdade de Direitos. $O$ quinze de novembro do sexo feminino. 6/4/1890. In: BERNARDES, M.T.C. Mulheres de ontem? Rio de Janeiro - século XIX. São Paulo, T.A. Queiroz, 1988, p.152.

${ }^{19}$ Isabel Dillon, ainda em vigência da monarquia, tentou alistar-se para votar. Como o voto era qualificado, usou como argumento a Lei Saraiva, que dava direito aos diplomados em cursos científicos. Alves, B. Ideologia \& Feminismo. A luta pelo voto no Brasil. Petrópolis, Vozes, 1980, p.91.
} 
Maternalismo, políticas públicas e benemerência no Brasil

Nas primeiras décadas do século $\mathrm{XX}$, os efeitos da urbanização, da industrialização, de melhor educação, bem como maiores oportunidades profissionais para o sexo feminino, se fizeram sentir na vida social. Intensificou-se a participação feminina em movimentos de reforma social e de reivindicações políticas. A professora Anália Franco e a médica Maria Rennotte, ambas colaboradoras do jornal $A$ Família, ampliaram o campo de ação, partiram para a prática $e$ fundaram entidades voltadas para a educação e para a saúde das mulheres e das crianças.

As entidades filantrópicas então criadas eram diferentes das associações de caridade de meados do século XIX. Enquanto as primeiras tinham sido organizadas e administradas por religiosos, visavam levar o conforto material e espiritual imediato para os necessitados, sobretudo, através de doações, tendo, portanto, pouco contato com os assistidos, as novas associações foram fundadas e dirigidas por mulheres, provenientes de uma ou de várias denominações religiosas. ${ }^{20}$ As sócias trabalhavam junto aos beneficiados e tinham por objetivos não só ajudar com doações, como também dar meios para que eles saíssem da situação de necessidade ou seja preocupavam-se com a promoção social. ${ }^{21}$

Os grupos criados, visando a defesa dos direitos políticos, não restringiam o campo de ação ao sufrágio feminino. Lutaram ao mesmo tempo pela emancipação jurídica, social, econômica $e$ intelectual das mulheres e pelo estabelecimento de leis de proteção à infância e à maternidade. $\mathrm{O}$ primeiro grupo feminista

\footnotetext{
${ }^{20}$ Em 1891, o Papa Leão XIII através da Encíclica Rerum Novarum convocou os católicos para se envolverem na promoção da justiça social, o que influiu na criação de grupos católicos voltados para as atividades benemerentes. SCHELL, P.A. An Honorable Avocation for Ladies. Op.cit.

${ }^{21}$ LEITE, M.M.S.B. Educação, Cultura e Lazer das Mulheres de Elite Em Salvador: 1890-1930. Dissertação de Mestrado, Salvador, Mestrado em História/UFBA, 1997, cap.4, pp.110-137.
} 
organizado foi fundado em 1910, pela professora Leolinda Daltro, na cidade do Rio de Janeiro. ${ }^{22}$

A situação das mulheres brasileiras, de modo geral, independente da origem social e étnica, era de grandes dificuldades e limitações. Tinham acesso ao ensino superior, mas não tinham muitas possibilidades de ingressar no curso secundário que lhes abria caminho para a faculdade; o marido era considerado o chefe na sociedade conjugal e sem sua autorização não podiam aceitar ou repudiar herança, exercer uma profissão, comprar ou vender, contrair obrigações que implicassem em alienação dos bens do casal, escolher o domicílio conjugal. As restrições legais não paravam aí: a viúva que voltasse a se casar perdia o pátrio poder sobre os filhos; as mulheres brasileiras que se casassem com estrangeiros perdiam a nacionalidade. As trabalhadoras recebiam salários menores que os homens pelos mesmos trabalhos realizados, sofriam assédio e maus tratos nas oficinas, não tinham regulamentado a licença maternidade e local para amamentar os filhos no serviço, bem como não eram aceitas como funcionárias em vários serviços públicos, inclusive nos Correios. $^{23}$

Em 1922 foi fundada, na cidade do Rio de Janeiro, a Federação Brasileira pelo Progresso Feminino (FBPF), considerada a organização feminista que obteve maior visibilidade e agregou o maior número de sócias no período. Possuía filiais em vários estados e teve uma atividade bastante intensa até 1937, quando foi instalada a ditadura do presidente Getúlio Vargas. O grupo era composto por mulheres educadas das camadas médias e das elites, muitas delas já militando individualmente ou filiadas a outras entidades feministas ou assistenciais. Tinha também como

${ }^{22}$ MARQUES, H. A construção da cidadania feminina no Rio de Janeiro. Revista do Instituto Histórico e Geográfico Brasileiro, Rio de Janeiro, 2000, pp.71-77.

${ }^{23}$ PENA, M-V.J. Mulheres e trabalhadoras... Op. cit.; MALuf, M., MotT, M.L. Recônditos do mundo feminino. In: NovAEs, F. (org.) História da Vida Privada no Brasil. República: da Belle Époque À Era do Radio. São Paulo, Companhia das Letras, 1998, pp.367-421. 
Maternalismo, políticas públicas e benemerência no Brasil

sócias mulheres profissionais das camadas mais simples, como professoras, comerciárias, datilógrafas.

A fundadora e principal porta-voz da Federação, Bertha Lutz, foi uma das primeiras mulheres a ter acesso a um cargo público de nível superior no país, tinha vivência no movimento feminista europeu e norte-americano, mas não era favorável a uma militância nas ruas no estilo das suffragettes inglesas, nem a movimentos grevistas como os realizados pelos operários $e$ operárias. Com a mesma convicção que defendia a emancipação econômica da mulher, a liberdade de exercer qualquer profissão independente do estado civil, os direitos políticos, defendia o lar como base da sociedade. Em 1936, Bertha escreveu:

não é exato nem procedente declarar que, adquiridos os direitos eleitorais, a mulher abdica do lugar que a natureza lhe concedeu. O domínio da mulher, todas nós feministas concordamos, é o lar. Mas é que hoje o lar não está mais compreendido no espaço de quatro muros. Lar também são a escola, a fábrica, a oficina. Lar é principalmente o parlamento onde se elaboram leis que regem a família e a sociedade humana ${ }^{24}$,

o que sugere que, para ela, educação, trabalho, emancipação não estavam em oposição, nem significavam rompimento com a família, com o papel de mãe e esposa, nem o desvio da missão educadora e altruísta da mulher na vida social e política.

A FBPF tinha como meta: 1. Promover a educação da mulher e elevar o nível de instrução feminina; 2. Proteger as mães $e$ a infância; 3. Obter garantias legislativas e práticas para o trabalho feminino; 4. Auxiliar as boas iniciativas da mulher $e$ orientá-las na escolha de uma profissão; 5. Estimular o espírito de sociabilidade e de compreensão entre as mulheres e interessá-las pelas questões sociais e de alcance público; 6 . Assegurar à mulher os direitos políticos e prepará-la para o exercício "inteligente"

${ }^{24}$ HAHNER, J. Emancipating the female Sex... Op.cit., p.149. 
desses direitos; 7. Estreitar os laços de amizade com os demais países americanos a fim de garantir a manutenção perpétua da Paz e Justiça no Hemisfério Ocidental. ${ }^{25}$

A FBPF buscou, por anos seguidos, instrumentos políticos para a obtenção do voto e de leis que beneficiassem as mulheres, inclusive as operárias, através de diferentes tipos de estratégias ditas legais. Aproveitou todas as brechas possíveis para abrir espaço para as mulheres desempenharem diferentes atividades; promoveu debates para influenciar favoravelmente a opinião pública sobre os direitos das mulheres; forneceu para a imprensa notícias sobre o movimento e sua programação, bem como respostas aos antifeministas; procurou apoio junto aos juristas $e$ políticos. Suas filiadas tentaram inscrever-se para votar, escreveram manifestos, petições, pressionaram deputados para mudanças legislativas, organizaram congressos feministas para os quais chamaram homens e mulheres de destaque dos diversos estados brasileiros e de alguns países estrangeiros o que deu grande visibilidade ao movimento.

Em 1922, a entidade organizou o I Congresso Internacional Feminista, no Rio de Janeiro, ao qual compareceu a líder sufragista americana Carrie Chapman Catt. Na ocasião, foram formadas comissões (trabalho, educação, direitos políticos e civis, proteção da infância e maternidade), das quais participaram representantes de organizações profissionais femininas, de assistência social e entidades filantrópicas. Valentina Biosca apresentou uma tese sobre o Trabalho Feminino nas Fábricas, através da qual pode-se avaliar a situação vivida pelas operárias e pelas crianças na indústria têxtil. As condições de higiene no

${ }^{25}$ As informações sobre a Federação Brasileira pelo Progresso Feminino foram levantadas em: Arquivo Nacional (FBPF, AP 46); SAFFIOTI, H. A mulher na sociedade de classes: mito e realidade. Petrópolis, Vozes, 1979, p.255-283; HAHNER, J. Emancipating the female Sex... pp.121-180; ALVES, B. Ideologia \& Feminismo. A luta pelo voto no Brasil. Obra citada, p.85-118; BESSE, S. Modernizando a desigualdade... Op.cit., pp.184-199; SCHUMAHER, S. \& BRAZIL, E.V. Dicionário Mulheres... Op. cit., pp.217-226. 
Maternalismo, políticas públicas e benemerência no Brasil

ambiente de trabalho eram as piores possíveis, as crianças $e$ mulheres sofriam abuso sexual, não havia regulamentação de horário de trabalho, a política de salário era prejudicial às mulheres. Recomendava o fim do turno noturno e a interdição de tarefas perigosas e pesadas para as mulheres, medidas de proteção para o aleitamento materno durante a jornada de trabalho, fiscalização sanitária dos estabelecimentos industriais, coibição do assédio sexual no local de trabalho, redução do tempo que as operárias deveriam ficar em pé. ${ }^{26}$

$\mathrm{Na}$ década seguinte, a FBPF organizou seu II Congresso Internacional Feminista (1931), também na cidade do Rio de Janeiro. As comissões pleitearam, entre outras medidas, sufrágio, mudanças na educação das mulheres no sentido de favorecer a profissionalização; organização de alojamento para mulheres universitárias; criação de um Departamento da Criança e da Mulher; inspeção feita por mulheres nos estabelecimentos fabris onde trabalhassem mulheres e crianças; direito a férias, salário mínimo e pagamento de acordo com o trabalho realizado, independente do sexo; sala de refeições e banheiros; licença maternidade; polícia feminina $e$ assistência social a cargo de mulheres; revisão da lei referente à nacionalidade da mulher casada e das penas nos delitos de crimes contra a honra, dito passionais. ${ }^{27}$

Estou convencida que a excelente documentação preservada pelo Arquivo Nacional referente a FBPF precisa passar por uma releitura no sentido de repensar o papel da entidade na luta por uma legislação social e trabalhista no Brasil. Muitas propostas discutidas por suas filiadas foram incorporadas à Constituição de 1934. Em 1930, o Brasil tinha passado por uma revolução. O novo governo, pressionado a restabelecer um regime constitucional, organizou uma comissão para preparar uma

${ }^{26}$ Schumaher, S. \& Brazil, E.V. Dicionário Mulheres... Op. cit., p.518.

${ }^{27}$ Arquivo Nacional. (FBPF, AP 46); BESSE, S. Modernizando a desigualdade... Op.cit., pp.189-90. 
minuta da nova Constituição. Bertha Lutz foi nomeada e, assessorada por advogadas associadas à Federação, apresentou as propostas discutidas e aprovadas nos Congressos Feministas. Dentre os itens incluídos na Constituição de 1934 estão: o direito das mulheres votar e serem votadas em situação de igualdade aos homens; de conservarem a nacionalidade e transmitirem aos filhos se casadas com estrangeiros; pagamento igual para trabalho igual; salário mínimo, limite de oito horas de trabalho diário; férias remuneradas; licença maternidade; direito de acesso das mulheres a funções públicas; participação das mulheres na direção $e$ administração de programas de assistência e bem-estar social relativos à maternidade e à infância. ${ }^{28}$

\section{IV}

Pérola Byington, como representante da Cruzada Pró Infância, foi ao Rio de Janeiro a fim de participar do II Congresso Internacional Feminista, organizado pela FBPF. Na Comissão de Proteção à Infância e Maternidade apresentou dois trabalhos "Pró Infância" e "Recreios Infantis" e fez quatro recomendações: 1) que fosse feito um apelo às mulheres brasileiras, visto acreditar que era responsabilidade, por excelência, do sexo feminino a proteção $e$ a defesa da criança; 2) que as associações educativas e sociais colaborassem na realização da Semana da Criança, no mês de outubro; 3) que fosse criado um seguro contra doença e invalidez e taxas especiais para obtenção de fundos para uma defesa da criança e da saúde pública; 4) que fosse estabelecido um salário mínimo "para abrandar a situação do proletariado". ${ }^{29}$

Quando da realização do II Congresso, a Cruzada ainda estava em fase de estruturação. Fundada em 1930 por um grupo

${ }^{28}$ Campahole, A \& Campahole, H.L. Constituições do Brasil. São Paulo, Atlas, $7^{\text {a }}$ ed., 1984, pp.540-541, 548-549; BESSE, S. Modernizando a desigualdade... Op.cit., pp.189-90.

${ }^{29}$ Sobre a participação da Cruzada Pró Infância no II Congresso ver: Arquivo Nacional (FBPF, cx. 38, AP 46). 
Maternalismo, políticas públicas e benemerência no Brasil

de mulheres de São Paulo, sob a liderança de Pérola Byington e Maria Antonieta de Castro, tinha por objetivos combater a mortalidade infantil através de um programa de assistência para as crianças e para suas mães. A mortalidade infantil era uma questão que preocupava as elites brasileiras. Se por um lado o desenvolvimento agrícola $e$ industrial fez com que o país conhecesse um surto de desenvolvimento, em especial nas cidades, o progresso não significou benefício para grande parte dos habitantes. Ao contrário, as desigualdades se acentuaram no período. Devido às péssimas condições sanitárias $e$ de trabalho, as taxas, sobretudo de mortalidade infantil, permaneciam altíssimas. ${ }^{30}$

Homens e mulheres educados das camadas médias e das elites passaram a denunciar esse "desperdício" de vidas para a nação. Dentro de um espírito populacionista da época, acreditavam que o Brasil precisava preencher os espaços vazios, que o número de habitantes significava maior número de trabalhadores, que o governo deveria investir mais na saúde da população que na imigração e que o futuro da nação dependia da quantidade, como também da qualidade física, moral e educacional de sua população.

A Cruzada Pró Infância surgiu justamente nesse contexto. A Presidente da Associação de Educadoras Sanitárias, Maria Antonieta de Castro teria entrado em contato com Pérola Byington para ajudar a desenvolver uma campanha de combate à mortalidade infantil. O grupo inicial foi composto por Madalena Sampaio de Oliveira e Maria Conceição Cardoso de Mello, ambas casadas com médicos sanitaristas, colaboradores por muitos anos com a entidade. Num espaço de poucos meses agruparam 100 (cem) "senhoras" e, em agosto de 1930, fundaram a entidade, que foi dirigida exclusivamente por mulheres. ${ }^{31}$

${ }^{30}$ Ribeiro, M.A.R. História sem fim... Inventário da Saúde Pública em São Paulo (1880-1930). São Paulo, UNESP, 1993.

${ }^{31}$ Ata da $1^{a}$. Reunião Geral Ordinária Cruzada Pró Infância 12/8/1930. Arquivo Cruzada Pró Infância. 
Pérola Byington foi diretora-presidente da Cruzada por mais de 30 anos, até 1963, quando morreu, e Maria Antonieta de Castro foi diretora-secretária pelo mesmo período. As duas podem ser consideradas as vigas mestras da entidade. Pérola Byington era descendente de imigrantes norte-americanos que vieram para o Brasil depois da Guerra de Secessão. Tinha então 50 anos, era casada com um importante empresário da área de eletrificação e do comércio de importação e desfrutava de um bom trânsito entre as elites com a qual vinha convivendo nos últimos quinze anos. Seu relacionamento de classe certamente não foi o único motivo $e$, talvez, nem mesmo o principal, do convite para formar a entidade. ${ }^{32}$ Ela era uma educadora com um projeto de reforma social e uma larga experiência em trabalho voluntário, realizado junto à Cruz Vermelha norte-americana e brasileira. Maria Antonieta tinha nascido no interior de São Paulo, era solteira, possuía uma trajetória importante como professora, educadora sanitária e escritora infantil.

Se as duas atuaram freqüentemente em sintonia - por exemplo, o trabalho apresentado por Pérola Byington, no II Congresso Feminista acima mencionado, foi escrito por Maria Antonieta - havia áreas de interesse diversificada. Os cursos de puericultura, a escola da saúde, os parques infantis eram sobretudo da alçada de Maria Antonieta, uma continuidade daquilo que fazia como educadora sanitária. Já a Casa Maternal, o Lactário (Banco de Leite), a defesa do salário maternidade, a

${ }^{32}$ Pérola Ellis Mc Intyre nasceu em 1879 , no interior de São Paulo. Sua mãe, Mary Ellis Mc Intyre, foi professora e dona de colégio. A ascensão social de Pérola ocorreu após o casamento. Em 1901, recém formada professora, foi convidada para ser governanta na casa de uma família da elite paulistana. Estando de casamento marcado com Albert Byington, um jovem empresário americano, recusou. Anos mais tarde, o filho do casal, acabou se casando com uma moça da mesma família que havia convidado Pérola para trabalhar! Alberto Byington era conhecido como "americano louco", pois comprava terrenos com cachoeiras para construir usinas para geração de eletricidade, ramo em grande expansão no período. Mais tarde, dedicou-se também ao comércio de importação. 
Maternalismo, políticas públicas e benemerência no Brasil

educação sexual e a criação de uma polícia feminina eram propostas defendidas por Pérola Byington, cujas fontes de informações foram adquiridas junto aos sanitaristas e puericultores brasileiros, mas também através de viagens feitas aos Estados Unidos, onde visitou diferentes entidades filantrópicas e órgãos governamentais, como o Children's Bureau, em Washington. Vale lembrar ainda que Pérola Byington era de formação protestante e Maria Antonieta era católica.

A proposta defendida por Pérola Byington no II Congresso Feminista - a organização pelas mulheres de uma Cruzada Nacional Pró Infância - era, na verdade, o programa de ação que vinha sendo posto em prática pela entidade em São Paulo. Incluía uma gama variada de ações, algumas mais imediatas, como prestar assistência material, moral, médica, sanitária, domiciliar e hospitalar para as crianças e suas mães, e outras de longo alcance, como educar as mães através de cursos de puericultura, pleitear junto aos poderes públicos a obtenção de leis favoráveis à gestante e à criança, supervisionar o cumprimento das leis, tornarse um centro de pesquisa e de informação sobre a infância, despertar a opinião pública para a defesa da criança e congregar as diferentes entidades $e$ associações que trabalhassem com essa questão.

Ao iniciar as atividades, a Cruzada contou com trabalho voluntário de suas associadas e entrou em contato com a sociedade civil para levantar fundos. Não tinha sede fixa, as reuniões eram realizadas em diferentes lugares $e$ os serviços prestados foram no sentido de ajudar individualmente algumas entidades, famílias e pessoas, com roupas, gêneros alimentícios, remédios, conselhos morais e até mesmo complementar os serviços de saúde e educação governamentais. Desempenhava então uma função assistencialista e funcionava como uma espécie de agência de empregos no sentido de encaminhar desempregados para o trabalho e clínica de aconselhamento familiar. Conta Pérola Byington que uma das primeiras tarefas realizadas foi oferecer apoio moral a uma menor de 16 anos que, 
depois de constatada a gravidez pelo médico do Centro de Saúde, foi maltratada pelos pais, expulsa de casa, chegando "às portas do suicídio". Entrando em ação um grupo de senhoras, conseguiu o perdão dos pais, o interesse do Juiz de Menores, a intervenção de um sacerdote, o consentimento dos pais da menor e do noivo da moça para "o feliz desenlace" do casamento. ${ }^{33}$

As propostas da Cruzada - de pleitear o estabelecimento de leis, criar programas e serviços de proteção à infância $e$ à maternidade e tornar-se um centro de produção de conhecimento - não foram esquecidas. Entre 1930 e 1945 pode-se dizer que a entidade se profissionalizou. As atividades e serviços se diversificaram e abrangeram um número maior de pessoas: foi construída uma sede, dispensários (com serviços de clínica geral, higiene infantil, pré-natal, fisioterapia, dietética, odontologia, dentre outros), uma Casa Maternal para acolher mães antes e depois do parto, foram organizados parques infantis com serviços de psicologia, criado um banco de leite, organizadas campanhas e cursos no sentido de divulgar os princípios de puericultura e, nos anos 40, fundadas creches. A entidade publicou uma revista própria, teve uma ativa participação em congressos e seminários que reuniam especialistas de diferentes áreas, apresentou trabalhos, fez e discutiu projetos, produzindo uma importante literatura sobre a proteção à infância $e$ à maternidade. ${ }^{34}$

Por várias vezes a Cruzada procurou influenciar as autoridades governamentais e legislativas no sentido de patrocinar novos programas em prol das crianças $e$ das suas mães $e$ fazer cumprir os direitos adquiridos. Algumas das propostas feitas estavam em sintonia com aquilo que era defendido pelo governo de Getúlio Vargas e foram incorporadas, outras só anos mais tarde, outras não tiveram êxito. Tendo sido objeto de discussão no

${ }^{33}$ Ata da $1^{a}$. Reunião Geral Ordinária Cruzada Pró Infância 12/8/1930. Arquivo Cruzada Pró Infância.

${ }^{34}$ A Cruzada Pró Infância - Histórico, desenvolvimento e realizações de 12/8/30 a 12/8/1949. Arquivo Cruzada Pró Infância. 
Maternalismo, políticas públicas e benemerência no Brasil

II Congresso Feminista a organização de Polícia Feminina no Brasil, Pérola Byington solicitou às duas policiais femininas inglesas, Comandante Allen e a Inspetora Tagart, que lá estiveram, para fazerem uma conferência em São Paulo, para a qual convidou o chefe da Polícia da Capital e o Juiz de Menores com o objetivo de implantar o mesmo serviço na cidade. Ainda em 1935, a diretora da Cruzada defendia a idéia pelos jornais. Em entrevista dizia que o cuidado das mulheres e dos menores infratores, "para ser perfeito deveria ser entregue à mulher". Não se tratava de criar uma polícia feminina "desvirtuada de suas finalidades", porém dentro da "missão da mulher" na sociedade. ${ }^{35}$

Outro projeto defendido por Pérola Byington, por anos seguidos, foi o do pagamento pelo governo de salário para as mães que não tivessem um "chefe". Entrou em contato com deputados/as e interventores, pedindo apoio para essa campanha, que chegou obter a repercussão desejada, ao que parece, em apenas um estado brasileiro. ${ }^{36}$ Uma das causas da mortalidade infantil, apontada pelos sanitaristas e incorporada pela Cruzada, era a ilegitimidade. O salário maternidade e a Casa Maternal, local para amparar as gestantes $e$ as mães necessitadas, eram vistos como formas de evitar o abandono.

O modelo de família preconizado era o de marido provedor e da esposa dependente voltada para os cuidados dos filhos. A família - constituída de pai, mãe e filhos - era considerada o sustentáculo da sociedade, mas a realidade social da maioria das brasileiras estava bem longe disso. Para Pérola Byington, todos deveriam lutar - igreja, governos, associações, imprensa, rádio, povo - no sentido de dar os meios necessários para assegurar a

${ }^{35} \mathrm{O}$ que vale dizer que acreditava que as mulheres conheciam melhor as necessidades das outras mulheres e das crianças. Assistência à mãe e à criança. Diário da Noite, 5/4/1935.

${ }^{36} \mathrm{Na}$ palestra "Como melhorar a alimentação na $1^{\text {a }}$ Infância" proferida por Pérola Byington em 22/9/1940 lê-se: "Nosso apelo não foi em vão (...) o Estado da Bahia atendendo-o houve por bem instituir uma pensão às mães, no intuito de fornecer a amamentação natural”. Arquivo Cruzada Pró-Infância. 
continuidade do "binômio sagrado - mãe e filho". ${ }^{37}$ Dizia que, a mãe no Brasil não estava protegida como deveria. "Nossa legislação social não a ampara. E isso é deprimente. Como avaliar o grau de progresso de um povo quando o mesmo não possui uma organização eficaz, padrão de serviço em maternidade?". Considerava a separação da mãe do filho desumana, contra "as leis naturais". Porém, não culpava as mulheres quando isso ocorria: "quantas vezes não abandona o filho temendo afrontar os preconceitos da sociedade que se mostra inflexível". Combatia os asilos, defendendo a colocação de crianças em lares substitutos ou o pagamento de um salário para as mães. Segundo ela,

a concessão de um pecúlio viria refletir benéfica $e$ profundamente nos lares onde faz sentir a ausência de um chefe encarregado da manutenção da casa e para o governo, redundaria em economia. Uma mãe sozinha com o filho é obrigada a relegá-lo para o segundo plano e procurar emprego. É claro, necessita, vai procurar trabalho e sua missão fica desviada com prejuízo para os filhos muitas vezes internados nos asilos do Estado. O maior prejuízo advém de que no futuro do homem se refletirá a ausência dos cuidados maternais indispensáveis na primeira infância. Trata-se antes de tudo de um fator psicológico social. A criança deve ser criada no lar onde adquire consciência de sua personalidade, e não num asilo onde se sentirá diferente de outras crianças protegidas no seio da família. $^{38}$

Assim como propunha um salário para as mães que não tivessem um "chefe" - vale ressaltar que ela usa a palavra "chefe" $e$ não marido, o que significa que defendia o mesmo benefício para mães solteiras - abria as portas da Casa Maternal para gestantes e mães, independente do vínculo matrimonial. A Casa

\footnotetext{
${ }^{37}$ Inicia-se amanhã a "Semana da Criança". Diário da Noite, 7/10/1938.

${ }^{38}$ Assistência à mãe e à criança. Diário da Noite, 0/4/35.
} 
Maternalismo, políticas públicas e benemerência no Brasil

Maternal foi inaugurada em 1932. O edifício foi cedido e reformado por Yayá Ribeiro da Luz e várias mulheres fizeram doações em dinheiro e objetos. Uma das estratégias utilizadas para levantar fundos foi dar a cada leito o nome de uma pessoa como forma de homenagem. O primeiro leito teve o nome da Dra. Maria Rennotte, fundadora da Cruz Vermelha em São Paulo e de um hospital para crianças, que doou móveis cirúrgicos. ${ }^{39}$ As mães eram assistidas até se restabelecerem e lá "recebiam conselhos amigos" e faziam alguns trabalhos. Quando eram "boas", lhes era arrumado um emprego, e a criança continuava sob a proteção da Cruzada até que a mãe pudesse se manter. A entidade não tinha estrutura para fazer partos; devido sua crença no parto como um evento hospitalar, encaminhava as gestantes para a Maternidade de São Paulo e para a Clínica Obstétrica da Faculdade de Medicina e as recebia de volta, depois de dar à luz, com a criança. Também amparava temporária e provisoriamente os filhos menores das parturientes que não tivessem com quem deixar em casa. ${ }^{40}$

Algumas gestantes eram encaminhadas para a Casa Maternal pelo Juizado de Menores, pela própria Maternidade de São Paulo ou pelo Asilo Bom Pastor, entidade fundada por religiosas católicas que atuava como uma espécie de recolhimento de mulheres que tinham procedido "fora das normas legais", mas que não acolhia mães com bebês. Em 1934, a Cruzada recebeu um ofício, solicitando a internação de uma menina de 12 anos, "débil-mental", por ter sido vítima de estupro e se achar grávida. Uma matéria publicada no Diário da Noite informa que naquele ano o Juizado de Menores tinha encaminhado 4 meninas abaixo de 16 anos. ${ }^{41}$ A Casa Maternal acolhia também mulheres pobres

${ }^{39}$ Cruzada pró infância. O Estado de São Paulo, 5/8/32.

${ }^{40} \mathrm{O}$ amparo dos filhos pequenos das parturientes $e$ o trabalho de acordo com a gravidez eram medidas usuais de entidades que tinham a mesma função. Ver: BeAuvalet-Boutoyerie, S. Naître à l'hôpital aux XIX siècle. Paris, Bellin, p.76.

${ }^{41}$ Assistência à mãe e à criança. Diário da Noite, 23/8/34. 
casadas, porém tinha como critério para o aceite a renda do marido. Vale ressaltar que não havia nenhuma outra instituição pública ou entidade religiosa na cidade de São Paulo, que prestasse o mesmo serviço que a Casa Maternal. Somente em 1939 foi criado por um grupo de médicos e religiosas católicas da ordem Franciscanas Missionárias de Maria, o "Amparo Maternal" e, em 1944, a "Casa Maternal Leonor Mendes de Barros", pelo governo.

O pagamento do leite materno foi mais uma das estratégias adotadas para não separar a mãe pobre da criança. Apesar de defender a amamentação, Pérola Byington reconhecia que havia casos em que as crianças não podiam receber leite de suas mães como doença, morte materna ou abandono da criança. Para tanto, em 1940 inaugurou um lactário humano onde era extraído leite materno mecanicamente para ser distribuído gratuitamente aos bebês. As doadoras eram submetidas a exames médicos e o leite por elas fornecido era pago para poderem sustentar o próprio filho em casa. ${ }^{42}$

A educação das mães foi uma das mais importantes campanhas desenvolvidas pela Cruzada ao longo desses anos. A ignorância, a falta de conhecimentos básicos de puericultura, a persistência de práticas tradicionais no cuidado das crianças, a amamentação artificial e a alimentação inadequada eram consideradas as principais causas da mortalidade infantil. A educação era realizada de diversas maneiras: por informações fornecidas durante as consultas, por aulas realizadas na própria entidade, promoção de diferentes cursos de puericultura $e$ realização de eventos, como a Comemoração do Dia da Criança e do Concurso de Robustez Infantil.

Mas as propostas de educação, muitas vezes, foram além dos princípios de puericultura e visavam ensinamentos sobre os

${ }^{42}$ Solenidades comemorativas do "Dia da Criança" nesta capital. Folha da Noite, 25/3/1940. O banco de leite criado na Cruzada foi o primeiro a ser criado no Brasil, se comparadas as datas mencionadas em ALMEIDA, J.A.G. Amamentação um hibrido natureza-cultura. Rio de Janeiro, Fio-Cruz, 1999. 
Maternalismo, políticas públicas e benemerência no Brasil

direitos maternos. Em 1933, Pérola Byington participou do Congresso de Proteção à Infância no Rio de Janeiro, onde apresentou um trabalho de sua autoria sobre "Educação Sexual e sua importância; como e quando ministrá-la". A educação sexual proposta deveria começar desde o primeiro ano de vida, feita em casa pela mãe. Porém, quando "o grau de cultura das mães" as impedisse de realizar esta missão, recomendava que fosse realizada nas escolas, por pessoas "de real valor intelectual $e$ moral". Propunha que o governo criasse um curso de Higiene Social nas escolas normais, cujo programa previa o ensino dos temas tradicionais como história natural, biologia, doenças venéreas, disciplina sexual, deveres dos indivíduos em matéria de higiene sexual, transmissão de enfermidades hereditárias, ilegitimidade, pornografia, aborto provocado, etc., como de temas que nem sempre se têm acesso nas escolas até hoje, por exemplo, os direitos das mães e das mulheres, investigação da paternidade, deveres da sociedade e do Estado para com a maternidade. ${ }^{43}$

A Cruzada também desenvolveu estratégias para apoiar as mães de diferentes camadas sociais que trabalhassem fora do lar, através da organização cursos de pagens e da luta pela criação de creches. Segundo Pérola Byington, não se discutia mais a capacidade, nem o direito da mulher ombrear com o homem em

${ }^{43}$ Byington, P. Educação Sexual e sua importância; como e quando ministrá-la. Anais da Conferência Nacional de Proteção à Infância. Ministério de Educação e Cultura, Rio de Janeiro, 1933, vol.3, pp.129-139. O programa de educação sexual era baseado nas propostas de Dra. Paulina Luisi, primeira mulher diplomada em medicina no Uruguai. A médica fundou naquele país, o Conselho Nacional das Mulheres (1916), a Aliança das Mulheres Feminina pelos Direitos das Mulheres (1920), a Associação das Mulheres Universitárias (1935). Publicou vários trabalhos sobre educação sexual, puericultura, direitos civis das mulheres, profilaxia das doenças venéreas, luta contra prostituição. Foi uma defensora da esterilização para de indivíduos que tivessem problemas genético e mentais, bem como do aborto para mulheres casadas obrigadas a manter, através da violência, relação sexual com os maridos. Ver: SILVA, A. A primeira médica do Brasil. Rio de Janeiro, Pongetti, 1954, pp.43-46; GuY, D. Pan American Child Congresses, 1916 to 1942. Journal of Family History, vol. 23, n 3, July, 1999, p.279. 
todos os campos de atividade e encargos da vida. O grande problema era a segurança dos filhos enquanto a mulher se ausentava do lar. Trazê-los ao mundo e prepará-los de forma a serem útil à coletividade eram os deveres primordiais da mulher, tarefa que considerava "bem pesada".

Porém quando a mulher necessita trabalhar fora do lar, para a sua manutenção, quando é solicitada freqüentemente a acompanhar o esposo em funções sociais, para sucesso deste, ou quando as ciências não prescindem da sua colaboração, o que lhe oferece a sociedade em troca do quase abandono do lar e dos filhos?. ${ }^{44}$

Por alguns anos, a Cruzada ofereceu um curso de pagens com o objetivo de formar moças para trabalhar em casas de família. O número de matriculadas em 1941 foi abaixo do esperado e nenhuma das formandas acabou indo trabalhar em casa particular, mas em berçários. ${ }^{45}$ Nos anos 40 , passou a defender a criação de creches, tendo inclusive desenvolvido um projeto junto a uma empresa. Vale destacar que nos primeiros dez anos de funcionamento, a Cruzada abrigava crianças pequenas apenas em casos excepcionais e temporariamente - quando a mãe estava internada na Casa Maternal, quando tinha sido abandonada e estava aguardando encaminhamento, crianças sãs de mães tuberculosas durante o período que fosse necessário para fazer efeito a vacina anti-tuberculosa, crianças doentes à espera de hospitalização, crianças doentes em tratamento. ${ }^{46} \mathrm{~A}$ luta pela fundação de creches significaria uma mudança de postura da entidade frente aquele que considerava o papel primordial das

${ }^{44}$ Byington, P. Fragmento datilografado. Dezembro de 1944. Arquivo Cruzada Pró Infância.

${ }^{45}$ Curso de Pagens. Folha da Noite, 14/10/1941.

${ }^{46}$ Pensões para mães cujos pais não assumem responsabilidade. Jornal do Comércio, 19/9/1935. 
Maternalismo, políticas públicas e benemerência no Brasil

mulheres? A documentação sugere que não. Além da "necessidade" da mãe trabalhar (não o direito), as justificativas apresentadas para a abertura de creches eram combater abandono e promover a educação das crianças. Ao que parece, Pérola Byington compartilhava da visão de muitas assistentes sociais que consideravam a creche como "um mal necessário". ${ }^{47}$

\section{V}

A história da Cruzada Pró Infância poderia ser realizada por vários ângulos, como por exemplo, o papel que a entidade teve na divulgação dos princípios de puericultura $e$ na disciplinarização do trabalhador, na medicalização e na promoção da hegemonia dos médicos na assistência ao parto ou, então, no desenvolvimento da especialidade da dermatologia pediátrica. Poderia ainda ser elaborada através da ótica dos concursos de robustez infantil ou da comemoração da Semana da Criança. Até mesmo as festas, quermesses, chás, torneios de bridge organizados para levantamento de fundos possibilitariam uma análise importante sobre o lazer na cidade de São Paulo. O estudo da entidade a partir do discurso maternalista, no entanto, ilumina uma série de questões fundamentais para se repensar a participação social e política das mulheres educadas das camadas médias e das elites na primeira metade do século XX, através das entidades benemerentes.

No período, a maternidade deixava de ser uma função individual, restrita à família, para ser uma função social. Era considerada como o papel primordial das mulheres que, em sua maioria, viam-na como um valor positivo. Acreditavam que através da maternidade obteriam reconhecimento social, direitos e igualdade - apesar de diferentes dos homens. Defendiam que a maternidade lhes atribuía qualidades específicas, naturais, para o

${ }^{47}$ TELLES, G.U. As creches como auxiliares das famílias. Monografia de conclusão de curso, Escola de Serviço Social, 1938. 
desempenho de determinadas atividades, sobretudo aquelas destinadas ao bem estar das mães e das crianças, e que era seu dever, face à nação, desempenhá-las.

Pode-se considerar o discurso maternalista "conservador", responsável pela perpetuação da subordinação das mulheres, por reproduzir a hierarquia entre os sexos e exigir que assumissem sozinhas os cuidados dos filhos; ou ainda, autoritário, uma forma de violência, pois não apenas as obrigava a serem mães independente da sua vontade, como também impunha às mais pobres a ideologia das camadas dominantes. Deixar, porém, de considerar a importância que teve até meados do século $\mathrm{XX}$ significa ignorar o imaginário das mulheres do passado e exigir crenças, propostas e atitudes que não eram suas. Faz também com que se perpetue uma análise equivocada e parcial da sociedade brasileira que exclui as mulheres associadas às entidades filantrópicas, seja da construção do Estado, como da luta pelos direitos das mulheres antes mesmo, e depois, de obterem o direito de voto.

Uma análise mais detalhada das propostas de Pérola Byington revela a complexidade do discurso maternalista e a necessidade de se fugir de uma análise linear, maniqueísta $e$ anacrônica. A Cruzada defendia o casamento e a família composta de marido, mulher e filhos - protegia, dava assistência e reconhecia os direitos de todas as mães; protegia e assistia as mães, fornecendo uma educação para que exigissem os seus direitos; ao mesmo tempo que defendia a maternidade, lutava para que a assistência ao parto estivesse dentro dos padrões considerados de qualidade.

A proteção à maternidade defendida pela Cruzada incluía todas as mulheres - as solteiras $e$ as casadas, as mulheres não trabalhadoras e as trabalhadoras de todas as categorias, inclusive as empregadas domésticas e as trabalhadoras rurais, que foram esquecidas pela legislação social e trabalhista até recentemente. 
Maternalismo, políticas públicas e benemerência no Brasil

Um repórter visitando o ambulatório da Cruzada se deparou com um cartaz com os seguintes dizeres ${ }^{48}$ :

A mulher, qualquer que ela seja, que encerra em seu seio um germe de vida e cheio de porvir, é sagrada.

A maternidade é uma função social que deve ser honrada, protegida e retribuída pela nação. A sociedade deve assegurar a toda a mulher durante a função maternal, as condições de higiene necessárias para o desenvolvimento normal da criança.

Toda gestação deve ser obrigatoriamente declarada, desde que seja provável.

Depois da declaração da gestação, durante a função maternal até o final da amamentação, a mãe e a criança devem ser submetidas a vigilância médica obrigatória.

A cada mulher será assegurado um médico parteiro.

Toda mulher, em estado de gestação - operária, industrial ou agrícola, empregada no comércio ou na administração, jornaleira (diarista) ou criada - deve cessar de trabalhar.

Toda criança tem direito ao leite e aos cuidados da mãe.

No período, o preconceito contra a maternidade fora do casamento era muito grande. Em 1937, foi feita uma consulta a um Procurador do Trabalho sobre o pagamento de meio salário de licença maternidade por 8 semanas a uma operária, conforme estabelecido por decreto em 1932. A alegação da empregadora para o não pagamento era de que a funcionária era solteira, que o pagamento concorreria para a dissolução da família legítima, um "menosprezo" às mulheres honestas, um péssimo e "repugnante" exemplo... ${ }^{49}$ A criação da Casa Maternal pela Cruzada certamente deve ter gerado polêmica, pois, na imprensa, Pérola Byington se defende numa entrevista, afirmando que esse tipo de assistência

\footnotetext{
${ }^{48}$ Cruzada Pró Infância. Diário da Noite, 11/4/1937.

${ }^{49}$ LOPES, H.X. Consulta, Previdência e Assistência Social. Boletim do Ministério do Trabalho, Indústria e Comércio, n ${ }^{\circ}$ 9, novembro de 1937, pp. 224-8.
} 
não ampliaria "o mal" mas, a falta de amparo sim, é que resultaria em problemas sociais. ${ }^{50}$

A documentação sugere, em vários momentos, que os serviços prestados na assistência ao parto, preconizados pela Cruzada, não deveriam ser de segunda categoria. No "Seminário das Mães", realizado em São Paulo em 1938, Pérola Byington propôs que fossem publicadas as causas das mortes maternas, com o objetivo de melhorar os serviços pré-natais e a assistência à parturiente..$^{51} \mathrm{~A}$ idéia foi discutida e não teve unanimidade, baseada em uma justificativa que demonstra a pequena importância dada à vida das mulheres por determinados setores da sociedade. Uma congressista alegou que esse tipo de publicação ia contra a obrigação de segredo profissional do médico e poderia agravar o problema da limitação da natalidade, pelo aumento do número de mulheres que passariam a temer a maternidade, o que vale dizer que a procriação antecedia o direito de uma assistência adequada às parturientes. ${ }^{52}$

A educação proposta pela Cruzada, conforme se viu, não se restringia apenas às obrigações e deveres das mães para com os filhos - para que não morressem e privasse a pátria de um trabalhador -, como também sobre os direitos enquanto cidadãs, visto a maternidade ser considerada uma função social.

A proteção à maternidade não foi a única luta da Cruzada. Nesses quinze anos, o leque de exigências feitas pela entidade incluía vários itens. Nem todas obtiveram o eco desejado, mas sua recuperação possibilita que se reflita sobre a amplitude das aspirações $e$ as necessidades sociais naquele momento. Ao lado

\footnotetext{
${ }^{50}$ Cruzada Pró Infância. Diário de São Paulo, 23/8/34.

${ }^{51}$ Pérola Byington traduziu para o português o texto de KRUIF, P. Chicago conserva a vida de suas crianças. São Paulo, Cruzada Pró - Infância, 1948, que relata a luta de Herman N. Bundsen contra a mortalidade materna e infantil naquela cidade. Uma das medidas lá tomadas foi a divulgação de estatísticas com as causa da morte materna com o objetivo de melhorar a assistência e punir os maus profissionais.

${ }^{52}$ Seminário das Mães. O Estado de São Paulo, 22/7/38.
} 
Maternalismo, políticas públicas e benemerência no Brasil

da regulamentação do trabalho dos menores, da criação do serviço de inspeção escolar, da regulamentação do exercício do esporte infantil, da educação no trânsito, da obrigatoriedade de um curso de pediatria para todos os médicos, da criação de sessões especiais de cinema para o público infanto-juvenil, defendia, entre outras reivindicações, o salário mínimo, melhoria das condições sanitárias, fiscalização do leite e da água, diminuição dos preços dos alimentos, aumento do salário dos médicos e educadoras sanitárias, que aceitassem colocação em postos de saúde no interior.

Entre 1930-1945, a Cruzada enviou ofícios ao legislativo propondo a criação e a aplicação rigorosa das leis; cobrou das autoridades e da sociedade civil várias medidas; buscou alianças para por em andamento seus projetos - com políticos, várias entidades benemerentes, grupos feministas, como também médicos, professores, educadores, psicólogos, assistentes sociais e empresários -; promoveu conferências e mobilizou a opinião pública através da mídia. Em 1932, quando da Revolução Constitucionalista em São Paulo, teve uma intensa participação no movimento, socorrendo a população civil, em particular, das famílias dos combatentes. A entidade recebeu apoio financeiro do Estado para suas obras, trabalhou em parceria com Estado em diferentes atividades, como também com empresários e até mesmo com uma associação de bairro, sugerindo que nem sempre a relação da entidade com os assistidos se dava de forma vertical. Durante a ditadura Vargas, viu a sua campanha pela comemoração da Semana da Criança ser incorporada e a Casa Maternal ser "copiada" pelo governo. Pode-se dizer que, em alguns momentos, supriu o papel do Estado, sobretudo, através de seus ambulatórios e parques infantis, tendo em vista a precariedade, ou até mesmo a inexistência, de alguns serviços oferecidos pela rede pública naquela época.

Para terminar gostaria de fazer algumas observações sobre a origem social das colaboradoras da Cruzada. O crescimento, o patrimônio adquirido, os compromissos assumidos pela entidade 
não comportavam o improviso. Todo esse trabalho foi organizado por mulheres das camadas médias e das elites. Pérola Byington e Maria Antonieta de Castro formaram uma equipe que administrou a entidade, gerenciou as verbas, contratou pessoal, resolveu, entre outros problemas, questões trabalhistas e de relacionamento entre funcionários. Não se pode esquecer, porém, que a credibilidade e o trânsito que a Cruzada teve entre o poder público, as elites, o empresariado e a mídia, certamente se deve em grande parte à origem social $e$ à rede de relações de suas principais colaboradoras.

O estudo da trajetória da Cruzada possibilita matizar algumas afirmações feitas sobre a participação das mulheres das elites nas entidades benemerentes, conforme mencionadas na introdução desse trabalho. Primeiro, não me parece que seja correto afirmar que a atividade benemerente foi sempre um subterfúgio para essas mulheres deixarem o lar e combaterem uma existência inútil; segundo, as atividades desenvolvidas tiveram como principal objetivo contribuir para a projeção social dos maridos. Tanto Pérola Byington como Maria Antonieta de Castro tinham um projeto de combate à mortalidade infantil bem definido, cuja implementação era considerada um dever patriótico. Maria Antonieta era solteira e já tinha uma vida profissional de destaque como escritora, professora e educadora sanitária, antes de iniciar sua Cruzada Pró Infância, ou seja não tinha marido para promover, nem precisava da entidade para justificar uma atividade profissional.

A biografia de Pérola Byington, por sua vez, possibilita que se matize, ainda, a afirmação de que as mulheres das camadas médias e das elites podiam mais facilmente participar do trabalho benemerente por estarem liberadas do serviço doméstico. A documentação sugere que as exigências domésticas feitas a essas mulheres, por elas mesmas e pela sociedade, eram de outro teor. Não se pode negar que tivessem menos trabalhos domésticos pois contavam com empregadas. Porém não se pode esquecer também que determinados cuidados com o marido e os filhos eram 
Maternalismo, políticas públicas e benemerência no Brasil

considerados exclusivamente seus. Conta uma neta que sempre que Albert Byington ficava na fazenda e Pérola Byington permanecia em São Paulo, ocupada com algum compromisso, não deixava, no dia seguinte, de chegar bem cedo, antes do café da manhã e preparar os biskets para serem comidos quentes. Certa vez o motorista se atrasou e, quando ela chegou na fazenda, viu que o marido já tinha tomado o café e saído. Surpresa, perguntou à cozinheira quem havia feito os biskets. Ao saber que a empregada tinha feito, Pérola Byington, geralmente "tão ponderada e pragmática perdeu a calma" e ficou um mês sem falar com a empregada!. ${ }^{53}$

${ }^{53}$ Byington, M.E.B. Pérola Ellis Byington. Uma vida a serviço do próximo. [Trabalho inédito.] 